\title{
Publisher Correction: Evolution of generalist resistance to herbicide mixtures reveals a trade-off in resistance management
}

David Comont (D), Claudia Lowe (D), Richard Hull, Laura Crook, Helen L. Hicks (D, Nawaporn Onkokesung (D), Roland Beffa, Dylan Z. Childs (1), Robert Edwards, Robert P. Freckleton (1) \& Paul Neve

Correction to: Nature Communications https://doi.org/10.1038/s41467-020-16896-0, published online 18 June 2020.

The original version of this Article contained errors in Fig. $2 \mathrm{~d}$, e, in which the $x$-axis labels were incorrect. 
The correct version of Fig. 2:

a



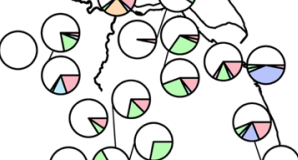

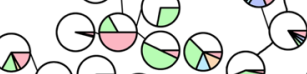



QQ

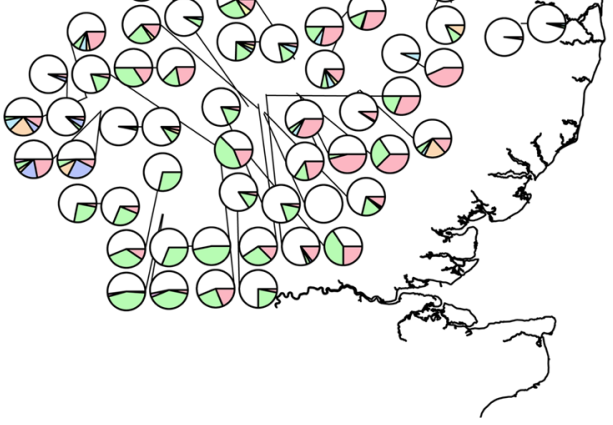

b


$\theta 8$

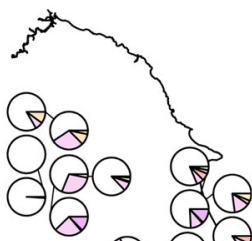

C

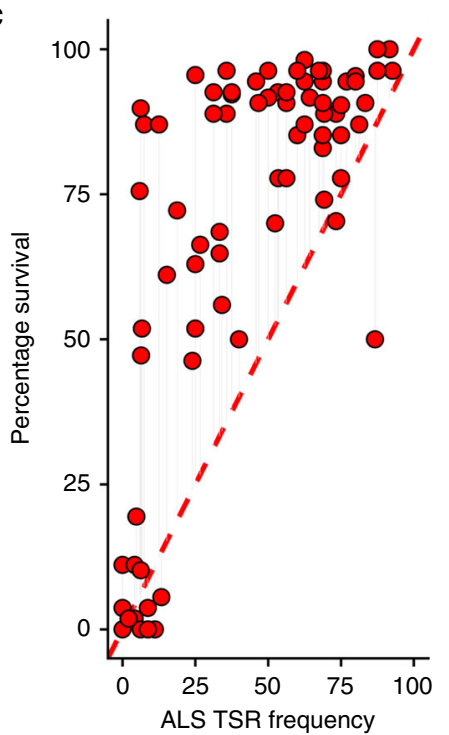

d

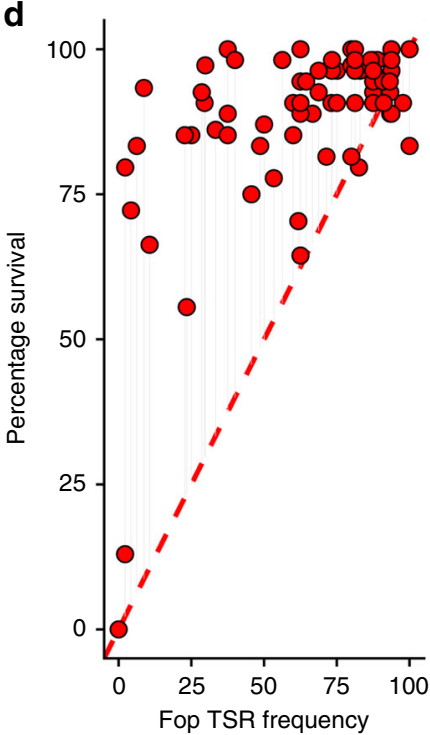

e

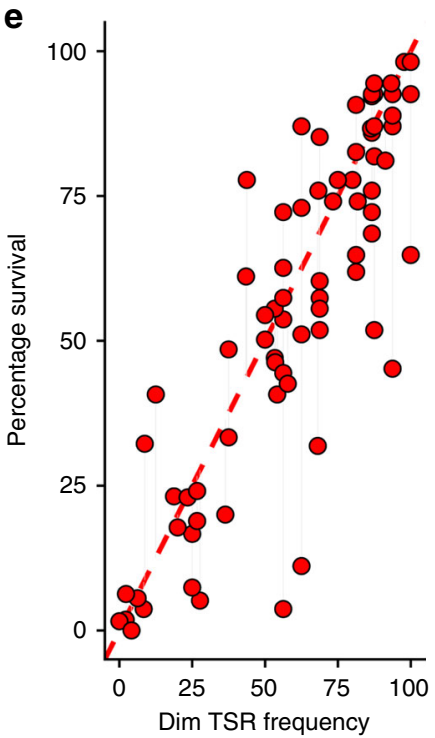

Fig. 2 
which replaces the previous incorrect version.

a

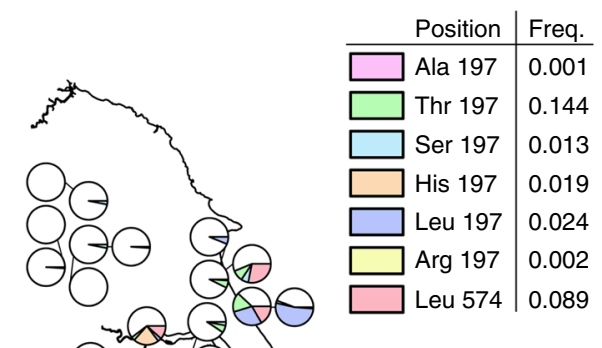

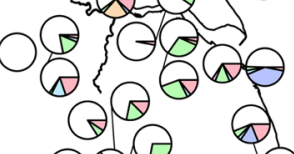

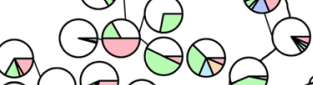
Q $\theta \otimes Q Q$

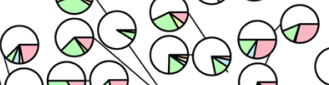

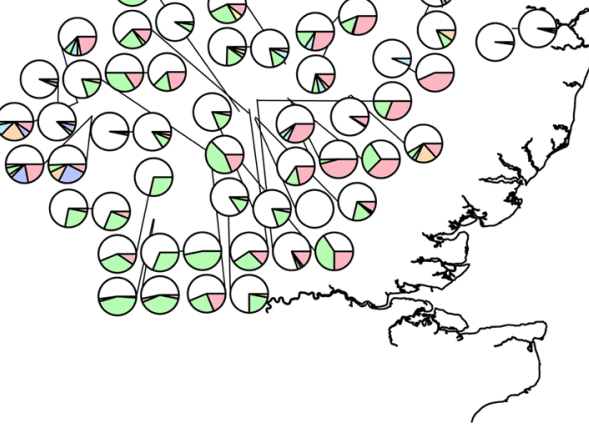

$\rightarrow$


c

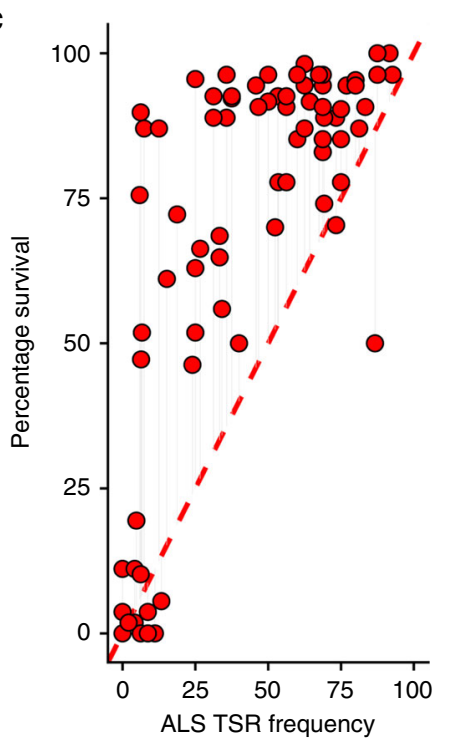

d

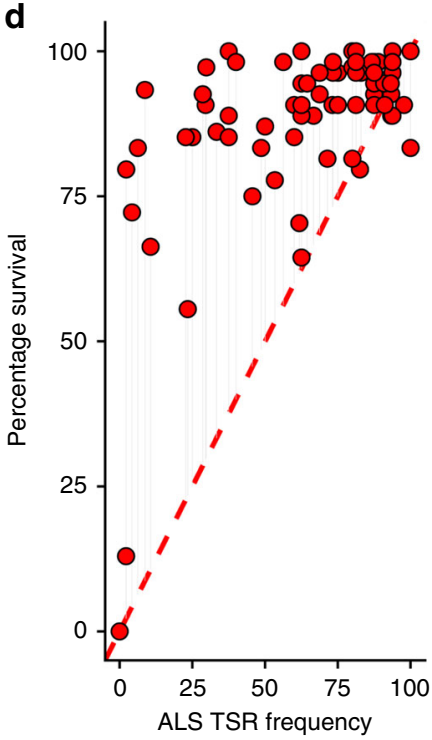

b

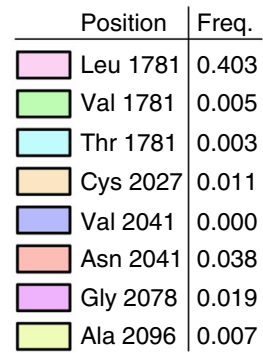

$\theta \theta$ $\rightarrow$ Ba<smiles>C1C2CC3CC1C3C2</smiles>

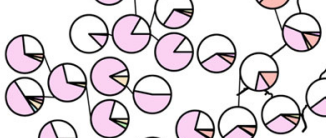
Q $\theta$ os $\theta$

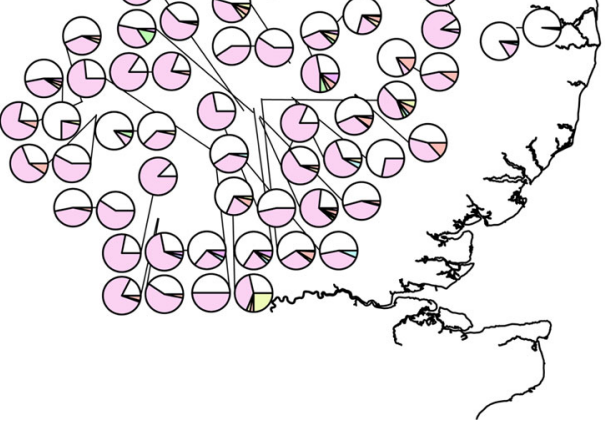

e

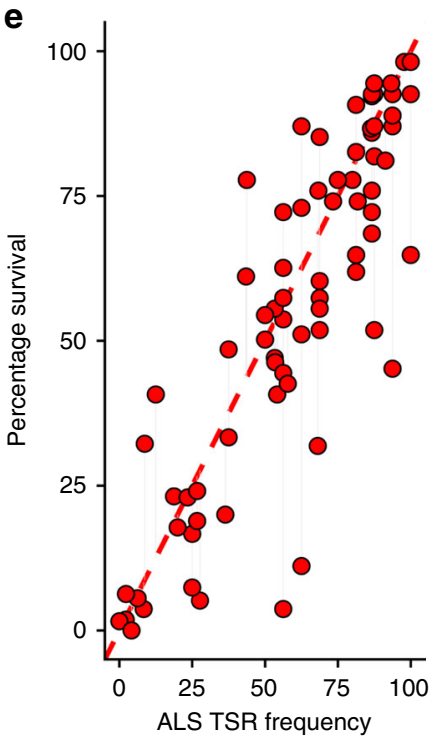

Fig. 2 
This has been corrected in both the PDF and HTML versions of the Article.

Published online: 02 September 2020

(c) (i) Open Access This article is licensed under a Creative Commons Attribution 4.0 International License, which permits use, sharing, adaptation, distribution and reproduction in any medium or format, as long as you give appropriate credit to the original author(s) and the source, provide a link to the Creative Commons license, and indicate if changes were made. The images or other third party material in this article are included in the article's Creative Commons license, unless indicated otherwise in a credit line to the material. If material is not included in the article's Creative Commons license and your intended use is not permitted by statutory regulation or exceeds the permitted use, you will need to obtain permission directly from the copyright holder. To view a copy of this license, visit http://creativecommons.org/licenses/by/4.0/.

() The Author(s) 2020 